DOI: https://doi.org/10.17648/2238-037X-trabedu-v28n3-15819

\title{
CONFIGURAÇÕES DA DOCÊNCIA EM UMA UNIVERSIDADE PÚBLICA NO BRASIL E NA ARGENTINA
}

\author{
Teacher configuration at public universities of Brasil and Argentina
}

FLORES, Maria Jose B. P. 1 DALBEN, Ângela I. L. de Freitas²

\begin{abstract}
RESUMO
Este artigo apresenta como objeto de estudo uma análise comparada da docência em uma universidade pública no Brasil e na Argentina a partir de dados da faixa etária e das condições de trabalho dos professores. Discute-se as configurações assumidas pela docência nestas universidades baseando-se na compreensão da educação superior como bem público e a profissionalidade docente estabelecida nesse processo. Considerando as transformações recentes no âmbito das universidades públicas da Argentina (as universidades nacionais) e do Brasil (as universidades federais), e reconhecendo as especificidades da constituição delas nos diferentes países, selecionou-se duas universidades com proximidades em termos de capacidade de atendimento e projeção no cenário acadêmico. Nesse contexto, realizou-se a pesquisa com 373 professores argentinos e 104 professores brasileiros, por meio de questionário e entrevistas semiestruturadas. Os resultados apontam uma disparidade de condições entre os docentes das duas universidades que podem ser compreendidos mediante uma leitura sócio-histórica do arranjo da educação superior nos respectivos países e suas influências sobre a universidade e, consequentemente, sobre a profissionalidade docente.
\end{abstract}

Palavras-chave: Docência universitária. Profissionalidade. América Latina.

\begin{abstract}
This article deals with a comparative analysis of teaching work at public universities of Brazil and Argentina taking into account data related to age groups and to working conditions of the professors. The way teaching work has been configured in these universities is discussed on the basis of considering higher education as a public good, and teaching profession being subjected to such a process. Both universities were selected in view of the similarities as to the logistics of the institutions as well as their projection into the academic community. Also they have been analyzed under the light of the recent reforms of public universities of Argentina (national universities) and Brazil (Federal universities). In this research, 373 Argentines professors and 104 Brazilian professors were subjected to questionnaires and semi structured interviews. It has been found differentiated teaching conditions between the professors of both universities that can be appraised through a socio-historical reading of the organization of Higher Education in each country, its influences on universities and, therefore, teacher's professionalism.
\end{abstract}

Keywords: University teaching. Professionalism. Latin America.

\footnotetext{
${ }^{1}$ Doutora em Educação pelo Doutorado latino-americano: Políticas Públicas e profissão docente. Professora Adjunta de Didática da Faculdade de Educação da Universidade Federal de Minas Gerais. E-mail: mariafloresufmg@gmail.com.

${ }^{2}$ Doutora em Educação. Professora aposentada da Faculdade de Educação da Universidade Federal de Minas Gerais. E-mail: tutti@uai.com.br.
}

Trabalho \&Educação | v.28 | n.3 | p.69-85 | set-dez | 2019 


\section{INTRODUÇÃO}

Este artigo apresenta como objeto de estudo uma análise comparada da docência em uma universidade pública no Brasil e na Argentina a partir de dados da faixa etária e das condições de trabalho dos professores. Discute-se as configurações assumidas pela docência nestas universidades a partir de uma leitura da educação superior como bem público e a profissionalidade docente estabelecida nesse processo.

A pesquisa foi realizada no âmbito de um doutorado em educação entre 2010-2014 e foi orientada pela seguinte questão: como se configura a docência entre professores das universidades públicas no Brasil e na Argentina no contexto atual e o que se acena em termos de profissionalidade?

Considerando as transformações recentes no âmbito das universidades públicas da Argentina (as universidades nacionais) e do Brasil (as universidades federais), e reconhecendo as especificidades da constituição delas nos diferentes países, buscamos selecionar duas universidades com proximidades em termos de capacidade de atendimento e projeção no cenário acadêmico. Nesse contexto, realizamos a pesquisa com 373 professores argentinos e 104 professores brasileiros, por meio de questionário e entrevistas semiestruturadas.

Os resultados encontrados apontam uma disparidade de condições entre os docentes das duas universidades que podem ser compreendidos mediante uma leitura sóciohistórica do arranjo da educação superior nos respectivos países e suas influências sobre a universidade, e consequentemente, sobre a profissionalidade docente.

Nesta perspectiva, organizamos este artigo abordando inicialmente a educação superior e a docência universitária na América Latina. Em seguida tratamos dos aspectos conceituais acerca da profissionalidade docente, apresentamos o percurso metodológico da pesquisa e por fim, expusemos os dados e analisamos as configurações assumidas pela docência universitária, encerrando o texto com as considerações finais.

\section{Educação SUPERIOR e suas PECULIARIdAdes na AmÉrica Latina}

Os estudos sobre a educação superior nas últimas décadas tem sido consensual na percepção de intensas transformações nesse campo em consonância com as transformações econômicas, políticas, sociais e culturais das sociedades contemporâneas. A educação superior tem ocupado lugar de destaque nas metas internacionais, regionais e nacionais; nas recomendações de Organismos Multilaterais; nas demandas de movimentos sociais; enfim, tem marcado presença nos diversos setores da sociedade demonstrando um campo de forças e disputas bem significativo no mundo atual.

Em termos regionais, na América Latina, em grande parte dos países, ocorreram amplas reformas no âmbito da educação superior, com tendências muito similares. Elas têm sido constantemente apontadas como sendo influenciadas por orientações internacionais advindas de acordos econômicos estabelecidos. (SILVA JÚNIOR, 1996; CATANI, 2002; MOLLIS, 2006; LEHER, 2010; MOROSINI E NOSIGLIA, 1998; entre outros.) 
De maneira geral, as transformações nos diversos países da América Latina têm sido marcadas por ações que impulsionam a internacionalização dos sistemas, expandem a educação superior pela via da privatização e diversificação institucional, estabelecem sistemas de controle e avaliação sistemática sobre as instituições e os sujeitos, entre outros aspectos. (Mollis, 2006, p.100)

Musselin (2011) explicita três fenômenos distintos que vêm marcando um processo de mercantilização ou industrialização do ensino superior no cenário global: um refere-se à transformação das universidades em organizações modificando suas formas de governanças, aproximando-as das gestões empresariais; outro diz respeito à mudança no sistema de produção de ensino e pesquisa cada vez mais voltado para a especialização de tarefas, racionalização e padronização; e, por fim, a mudança de concepção do ensino e pesquisa como bens públicos para bens privados. (MUSSELIN, 2011, p. 325)

Considerando o contexto latino-americano Mollis (2006) explicita traços semelhantes nas reformas implementadas na década de 1990 em países como: Argentina, Bolívia, Brasil, México e Uruguai. Preservando algumas peculiaridades, observa-se nas reformas empreendidas nesses países o estabelecimento de novas legislações para educação superior seguindo os parâmetros internacionais. Tais legislações seguem vigentes.

O conjunto de ações predominantes nas reformas da educação superior na América Latina, juntamente com a história e o percurso da educação em cada país, tem evidenciado um cenário de comprometimento "do acesso, da qualidade e da equidade da educação", conforme analisa Didriksson (2008):

\begin{abstract}
En este nuevo siglo, el panorama de la educación superior, sin embargo, se mantiene en una suerte de impase y a la expectativa, porque a pesar de que se observa la fragmentación y heterogeneidad del modelo predominante, con un conjunto de nuevas instituciones de diferente carácter y nivel (privadas y públicas, universitarias y no universitarias, politécnicas, tecnológicas, de ciclos cortos, comerciales, entre otras), y que se alcanzó una nueva oleada de expansión de la demanda hacia la educación superior, se han reproducido a mayor escala, las más grandes desigualdades y inequidades, a nivel de género, de raza y de etnia, así como de forma pronunciada a nivel de las condiciones socio-económicas de ciertos sectores de la población, junto a la idea de que la lógica del mercado es uno de los mejores referentes de la calidad educativa, mientras encuentran amplios cauces de expansión las empresas de transnacionalización y de mercantilización del servicio educativo respectivo (DIDRIKSSON, 2008, p.25).
\end{abstract}

A constatação dessa desigualdade e a iniquidade presente na educação superior latino-americana evidenciam como vivemos distantes em termos da educação entendida como um bem público. Como explicita Azevedo (2010), compreender a educação nessa dimensão implica considerar as seguintes condições: "1.0 acesso ao bem não pode ser exclusivo a um contingente de modo que possa significar o não acesso por parte de outros cidadãos (não rivalidade); 2.0 acesso ao bem não pode implicar em diminuição de seu conteúdo para o outro (não excludência)." (AZEVEDO, 2010, p.165).

Recorrendo a alguns dados levantados pela Unesco sobre a educação superior nos países da América Latina fica evidente o tamanho do desafio a enfrentar quando se toma a educação superior na perspectiva de um bem público. 
Quanto ao acesso à educação superior em termos numéricos, observa-se um crescimento superior a 50\% nas matrículas nesse nível de ensino na América Latina entre 1994 a 2006 (de 7.544 para 17.017 matrículas). Entre os países: Brasil (4.802.07 matrículas), México (2.709.25 matrículas) e Argentina (2.173.96 matrículas), o total de matrículas em 2006 foi superior a 60\%. (GAZZOLA, 2010, p.38) No entanto, esse percentual de matrícula não confere acesso irrestrito aos jovens em idade correspondente ao ensino superior. No Brasil, por exemplo, observa-se um caso emblemático: o atendimento à população entre 18 a 24 anos correspondeu a 13,9\% da demanda em 2009. (GOMES, 2011, p.29)

Além desse aspecto, a concentração de estudantes em instituições públicas e privadas varia significativamente, entre os países:

Los países que tienen una concentración de estudiantes de entre el $75 \%$ y el $100 \%$ en instituciones de carácter público, son Cuba, Uruguay, Bolivia, Panamá, Honduras y Argentina. Los que tienen el mayor porcentaje (de entre 50 y 75\%) de estudiantes en instituciones de carácter privado, son Brasil, Chile, El Salvador, Colombia, Costa Rica, Nicaragua y República Dominicana. En una situación intermedia, por así decirlo, esto es, países que tienen concentraciones de estudiantes importantes tanto en el sector público como en el privado, están Ecuador, México, Venezuela, Paraguay, Perú y Guatemala. Sin embargo, debe notarse que la tendencia de incremento de la participación de las instituciones de educación superior privadas ha ido en aumento en la región de forma constante (DIDRIKSSON,2008, p.30).

Esses indicadores mostraram não só a diferença de condição da educação superior entre os países, mas também a distância da maioria deles em relação à oferta de educação superior como bem público. Observa-se o desafio em dar conta do princípio básico de universalização do ensino superior.

Nesse contexto, a importância de um olhar atento sobre a docência universitária como uma dimensão relevante para compreender as orientações sociopolíticas e culturais da educação superior nos distintos países.

\section{DocÊnCIA UNIVERSITÁRIA NO ÂMBITO dA AMÉRICA LATINA}

Embora quase sempre os docentes sejam vistos apenas do ponto de vista da qualificação, como indicador de qualidade da educação superior, sabe-se que isso é insuficiente para analisar a docência universitária. É importante, além da qualificação, a garantia de condições básicas para o trabalho, como: suportes materiais adequados, possibilidade de dedicar-se integralmente ao trabalho, adequada remuneração, liberdade de produção dos conhecimentos, entre outros. Contudo, verifica-se que, atualmente, as transformações ocorridas na educação superior têm impactado a condição profissional dos docentes, fenômeno esse evidente no relatório da conferência mundial da educação superior promovida pela UNESCO em 2009.

Segundo Altbach (2009), para entender a profissão acadêmica contemporânea é útil examinar seu estatuto e as condições de trabalho. Em sua opinião, trata-se de uma profissão que tem apresentado um comportamento demográfico de envelhecimento em termos mundiais e mostrado cada vez mais segmentada e diferenciada. Portanto, é quase impossível tratar da profissão como um todo. (ALTBACH, 2009, p. 89)

Ele ainda aponta alguns fenômenos que vêm impactando os docentes em escala mundial mostrando a "centralidade e crise da profissão acadêmica" contemporânea: 0 
predomínio do exercício da docência part-time 3 ; a baixa remuneração; a burocratização do trabalho acadêmico com perda de autonomia do professorado; e, ainda, o mercado global que tem levado os docentes a migrarem de seus países de origem em busca de melhores condições em outros.

Na América Latina, os dados sobre docentes com dedicação integral revelam baixa quantidade de docentes nessa condição, indicando o predomínio de docentes parttime, no âmbito do ensino superior, na maioria dos países pesquisados, como mostra o gráfico a seguir:

Gráfico 1- Número de docentes com tempo integral por 1.000 matrículas em países latino-americanos

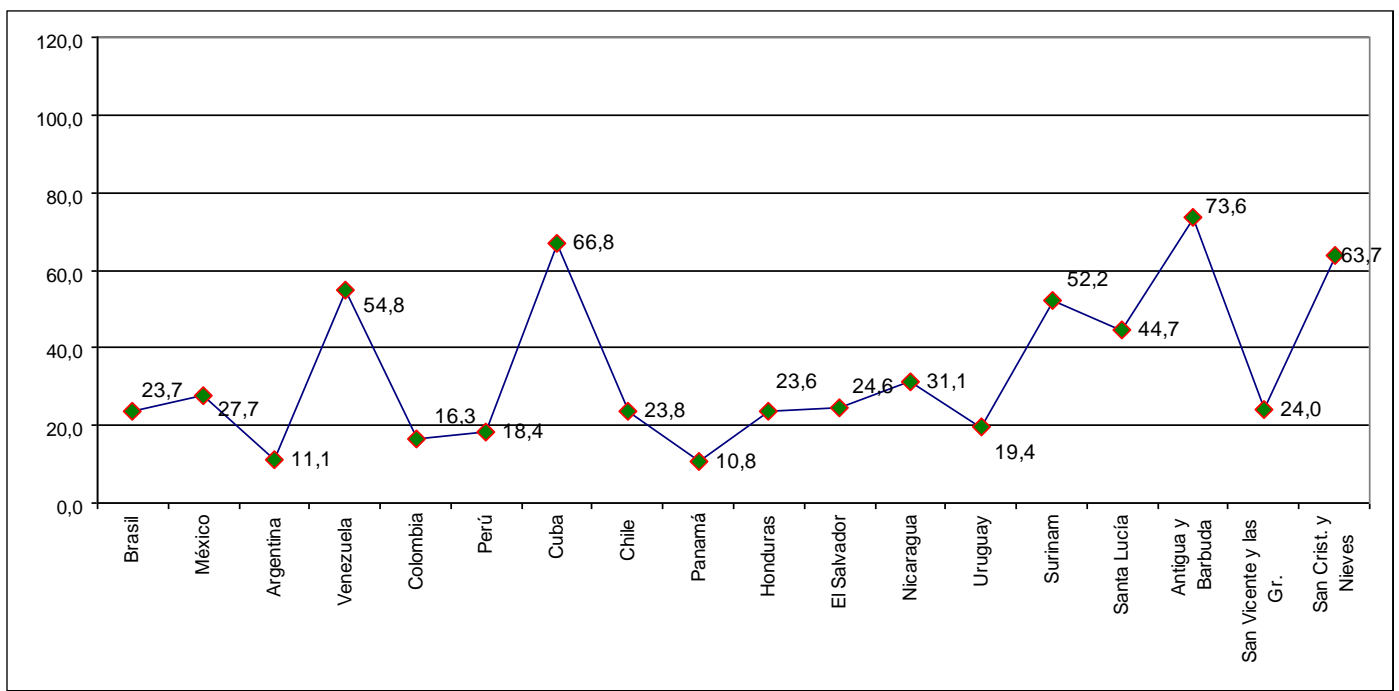

Fonte: GAZZOLA, 2010, p.28

Conforme os dados acima, apenas três países apresentam mais 60 docentes com dedicação integral para mil matrículas no ensino superior, evidenciando melhores condições de dedicação ao trabalho.

Em outro extremo, observam-se países com cerca de 11 docentes em tempo integral para mil matrículas, como a Argentina e o Panamá. E há maior concentração dos países com 15 até 30 docentes por mil matrículas, entre os quais se encontra o Brasil, com 23,7 docentes para mil matrículas. Conforme Altabch (2009) esse quadro mostra que a vivência da profissão tem levado o docente a ser denominado professor-táxi em alguns países, isto é, aquele professor que, durante uma jornada de trabalho, percorre duas ou mais instituições para dar aula.

Nessas circunstâncias, pode-se dizer que o docente se encontra em condições limitadas para desenvolver um conhecimento crítico e sistemático, tendendo muito mais a reproduzir que propriamente criar conhecimento que atenda à realidade social em que vive. A dimensão pública da educação superior, como tratado Azevedo (2010), torna-se comprometida, pois não há docentes suficientes e em condições satisfatórias para atender a todos os alunos e promover produção de conhecimento.

${ }^{3}$ Refere-se a uma instituição que não proporciona aos docentes dedicação integral ao trabalho. Por exemplo: 20 horas semanais, 10 horas semanais, 04 horas semanais e outros na instituição. Essa situação faz com que os docentes trabalhem em muitas instituições ao mesmo tempo para completar carga horária semanal de trabalho suficiente para suprir suas necessidades. 
Além da dedicação integral, outro dado sobre os docentes na América Latina a ser ressaltado: prevalência de pouca formação em pós-graduação stricto sensu na maioria dos países. O Brasil e o México são os que apresentam maior proporção de docentes com doutorado, respectivamente: 14,71 por mil matrículas e 10,64 por mil matrículas. Os demais países apresentam menos de 6 docentes doutores por mil matrículas. (GAZZOLA, 2010, p.29)

Nesse sentido, cabe pensar a docência no contexto das universidades públicas da América Latina. São estas instituições que mais sofreram mudanças e ajustes nas últimas décadas: "la universidade latinoamericana y caribeña encara hoy fuertes dilemas, tendencias y retos, que debe resolver, considerar y enfrentar." (DIDRIKSSON, 2008, p.32)

De acordo com esse autor, as universidades públicas modificaram suas estruturas e organização em condições difíceis: de pouco financiamento e muitas demandas de adaptação às novas formas de produção de conhecimento e tecnologia. Contudo, ainda são as universidades públicas que abrigam a maior quantidade de investigadores na América Latina: 65,1\% do total (DIDRIKSSON, 2008, p.30).

Quanto à produção acadêmica na América Latina, os dados indicam crescimento considerável entre 1990 a 2006 partindo de 1,7\% para 3,7\% da produção mundial. Os quatros países que apresentaram maior número de artigos publicados em revistas indexadas, em 2006, foram respectivamente: Brasil, México, Argentina e Chile (GAZZOLA, 2010, p.33).

Afinal não somente pela pesquisa, mas também pelas demais funções de uma universidade e pela sua posição como uma instituição social, pode-se afirmar que essa instituição cumpre uma função importante no âmbito do ensino superior. No entanto, o cenário apontado por Didrikson (2008) demonstra que as mudanças ocorridas entre as universidades latino-americanas se aproximam do que Musselin (2011) e Chauí (2003) identificam como transformação das universidades públicas em organização. Processo que cria efeitos entre os sujeitos que nelas atuam, especialmente, a condição dos docentes cujo trabalho e produção situam e se afirmam nesse contexto.

Frente a esse panorama, buscamos a seguir tratar dos aportes conceituais com os quais analisamos a docência em uma universidade no Brasil e na Argentina.

\section{DOCÊNCIA UNIVERSITÁRIA E PROFISSIONALIDADE}

A docência universitária é entendida neste estudo como as atividades desenvolvidas pelo magistério docente na educação superior. Portanto, se considera que:

Insere-se na condição ampla da profissão professor, assumindo as representações e ações próprias da função de ensinar. Amplia, porém, o espectro de responsabilidades profissionais, incluindo as características peculiares do espaço onde se instala que prevê também as ações de pesquisa, extensão e gestão (CUNHA, 2010, p.1).

Tomando essa noção como ponto de partida, consideramos que ela apresenta dois eixos articuladores para compreensão conceitual da docência universitária: a condição ampla de profissão professor e as suas particularidades relativas às funções assumidas no âmbito do ensino superior, especialmente, na universidade. 
O entendimento da docência na perspectiva da profissão nos exige a compreensão de que, conceitualmente, a noção de profissão não dá conta da realidade empírica do trabalho docente, tendo em vista a complexidade que o envolve em termos de atividades de trabalho e posicionamento como grupo ocupacional.

No entanto, a profissão entendida como a representação de uma atuação profissional qualificada por determinados atributos tem sua validade como referência discursiva e por isso, sua pertinência enquanto identificação mais ampla.

Do ponto de vista analítico temos, a partir da sociologia das profissões, a busca por um entendimento mais processual e interacionista das profissões como objeto de estudo, do qual derivou a noção de profissionalização, vista como "uma sequência de eventos ou etapas seguida pelos grupos ocupacionais até o estádio do profissionalismo." (RODRIGUES, 2002, p. 17)

As análises dos processos de profissionalização docentes levaram a percepção de várias ambiguidades que perpassavam a docência como grupo profissional: heterogeneidade na composição, feminização, processos de proletarização combinados com um tipo de atividade intelectual e socialmente relevante. (Cunha, 2007; Enguita, 1991)

Assim, a profissionalização docente é construção sócio-histórica e política que lhe confere variações de acordo com o contexto societal e as condições de escolarização. (TARDIF; LESSARD, 2009) Os professores constituem "grupos profissionais específicos em cada país, em razão de sua história, de suas características socioculturais e da organização criadas por eles." (LANG, 2008, p.665) Também sofrem influências das mudanças nas missões das instituições educativas assim como das transformações societais como atualmente, os novos modos de acesso a informação e comunicação. (LANG, 2008)

Portanto, assegura-se aqui que a profissionalização docente remete a fatores complexos que envolvem a atividade profissional em sua ação específica, e em sua condição de realização, influenciada pela dimensão organizacional e pelas relações de poder estabelecidas. (LANG, 2008)

Diante desta complexidade que envolve o entendimento da profissionalização docente e a dispersão discursiva em torno dessa noção, alguns autores têm apontado o termo profissionalidade, como o mais adequado para tratar da docência dada a especificidade do seu trabalho.

Cunha (2007), remete à definição dada por Sacristán (1993) para a profissionalidade como "a expressão da especificidade da atuação dos professores na prática, isto é, o conjunto de atuações, destrezas, conhecimentos, atitudes e valores ligados a ela, que constituem o específico de ser professor." (SACRISTÁN,1993, p.54 apud CUNHA, 2007,p.14)

Nessa perspectiva, a noção de profissionalidade coloca no centro da compreensão da docência, os professores como sujeito socioculturais, portadores de uma função que abarca não só aspectos técnicos, mas também políticos, oriundos tanto da experiência pessoal quanto do trabalho e da formação em vista de uma intencionalidade mais ampla e compartilhada coletivamente.

A profissionalidade docente envolve dimensões relativas à condição profissional e as exigências da prática docente abrangendo "as condições e restrições da realidade 
educativa, assim como, das formas de viver e desenvolver a profissão enquanto atitudes e destrezas postas em jogo pelos membros concretos da profissão." (CONTRERAS, 2002, p.75)

No que tange à docência universitária é comum considerá-la como a profissão das profissões dado o lugar que a universidade ocupa na formação profissional. Ao mesmo tempo, os docentes universitários são retratados a partir da comparação com os docentes dos demais níveis de ensino. Enguita (1991), ao tratar da heterogeneidade da docência, já assinalava sinais de mudanças entre os docentes universitários, ao dizer que:

\begin{abstract}
A posição dos professores universitários tem-se degradado relativamente não tanto por uma queda de suas condições materiais como pela expansão da categoria, que tem passado de ser uma minoria muito restrita a já não sê-lo tanto; isto, quando menos, traduzse em perda de prestígio e distinção, se não coletiva, pelo menos individualmente. (ENGUITA, 1991, p. 56)
\end{abstract}

Quase três décadas posteriores a essa análise de Enguita (1991), em termos globais, pode-se dizer que a educação superior e, consequentemente, as universidades têm passado por mudanças substantivas tendo, como um dos efeitos, a mudança da fisionomia da categoria docente: maior quantidade, diversificação interna com desigualdade de condições, entre outros.

Santos (1995) considera que essas são alterações imediatas e visíveis em curto prazo. Subjacente a elas, vislumbra-se alterações a longo prazo, como a mudança do grau de respeito aos valores da ética científica: "o comunismo, o desinteresse, o universalismo e o cepticismo organizado" (SANTOS, 1995, P.204) às quais a comunidade universitária sempre aspirou com maior ou menor concretização.

\title{
O PERCURSO METODOLÓGICO DA PESQUISA
}

Esta pesquisa foi orientada por um estudo comparado, pois foi desenvolvida no contexto de um programa de doutorado que focalizava a América Latina como espaço a ser considerado nas investigações.

Nesse sentido buscamos referenciar-nos em uma perspectiva sócio-histórica no enfoque comparado, tal como preconizado por Nóvoa (1995), Krawczyc (2003), Zelmeman (2003). Esses autores defendem uma abordagem comparada que considere as especificidades históricas dos fenômenos estudados em detrimento de uma abordagem homogeneizante das distintas realidades. Trata-se de construir o objeto da comparação passando da análise dos fatos à análise do sentido histórico dos fatos, portanto, tem uma possibilidade compreensiva de grande valor epistemológico, pois permite conhecer um determinado contexto em relação com o outro, dando atenção às singularidades específicas e as interações estabelecidas que nos desafiem à explicação das diferenças contextuais.

Seguindo essas orientações, a escolha pelos dois países se deu em função de estarem localizados na América Latina e possuírem características relevantes em relação à educação superior que poderia contribuir para um entendimento crítico acerca dos docentes nesse nível de ensino.

Brasil e Argentina são países vizinhos, localizados na América do Sul e que têm compartilhado as tendências sobre a educação superior nas últimas décadas e, ainda, 
apresentam algumas semelhanças e disparidades, tais como: estão entre os quatros países latinoamericanos que apresentam maiores produtividade acadêmica e que levaram, de maneira mais efetiva, as reformas na educação superior dos últimos tempos; por outro lado, a quantidade de docentes em tempo integral na Argentina equivale à metade da quantidade de docentes em tempo integral no Brasil; e o Brasil está entre os países que apresentam mais oferta de ensino superior privado e possui ingresso seletivo dos estudantes a Argentina, entre aqueles de maior oferta pública e tem estabelecido o ingresso irrestrito dos estudantes.

Morosini e Nosiglia (1998) ao analisarem o contexto do Brasil e da Argentina, mostram como os diagnósticos elaborados pelos governos dos respectivos países, para implementar as reformas da década de 1990 seguiam as mesmas tendências. Divulgavam dados que induziam uma avaliação que indicava a ineficiência das universidades públicas na gestão dos recursos e atendimento à população. Para tanto, propunham políticas que implicavam uma nova relação entre Estado e universidades. Assim, emergiam propostas nas quais as universidades perdiam autonomia na gestão de seus recursos, cujo acesso se dava por meio de contratos de resultados.

Nesse contexto, a escolha por abordar docentes de universidade públicas, se fez mediante a leitura de que as universidades públicas são as instituições que mais sofreram impactos com as mudanças ocorridas na educação superior e ao mesmo tempo, são elas, as instituições que abrigam a maior quantidade de investigações na América Latina (Didriksson, 2008).

Assim, ainda nos restavam delinear quais universidades e qual o grupo de docentes seriam estudados. Propusemos focalizar universidades públicas que fossem vinculadas ao governo nacional dos respectivos países (uma universidade federal brasileira - Universidade BR e uma universidade nacional argentina - Universidade AR). No universo de instituições dessa natureza, identificamos aquelas cujos contextos se aproximavam e elegemos duas instituições considerando-se: proximidade no universo de cursos oferecidos (cerca de 75 cursos), referências em termos de produção de pesquisa com repercussão nacional e internacional, localização em grandes centros urbanos e por fim, que aceitassem a proposta de pesquisa.

Esclarecidas as particularidades de ambas as universidades, foram selecionados grupos de professores de três cursos (Engenharia Eletrônica, Odontologia e das Faculdades de Educação ${ }^{4}$ ), contemplando diferentes áreas de conhecimento (exatas, humanas e saúde), com o intuito de preservar as distinções epistemológicas que estão presentes na docência de ensino superior proveniente da natureza das disciplinas. Optou-se ainda, em cada grande área, por realizar a pesquisa com grupos de professores de áreas aplicadas. Essa escolha baseou-se na literatura, cujos discursos reiteram que essas áreas têm sido submetidas às referências de produção acadêmica própria das áreas básicas. Isso afeta o trabalho dos docentes que passam a ser regidos por uma lógica que não respeita as especificidades das diversas áreas.

Esse critério nos colocou diante de uma quantidade considerável de grupos de professores que trabalham com áreas aplicadas. Desse modo, decidimos fazer a pesquisa com aqueles que fossem acessíveis, daí decorreu a pesquisa com professores de Engenharia Eletrônica, Odontologia e Educação.

\footnotetext{
${ }^{4}$ Nesse texto, trataremos a identificação dos docentes, referindo-se apenas às áreas engenharia, odontologia e educação. 
Nessa perspectiva, o trabalho de campo envolveu a coleta de dados por meio de questionários e entrevistas, perfazendo um total de 477 questionários e 49 entrevistas. $\mathrm{Na}$ Universidade BR foram 104 questionários (58 odontologia, 28 engenharia, 18 educação) e 17 entrevistas (07 odontologia, 07 engenharia e 03 educação). Na universidade AR foram 373 questionários (259 odontologia, 89 engenharia, 25 educação) e 32 entrevistas (11 odontologia, 11 engenharia e 10 educação)

Buscamos analisar os dados por meio de estatística básica e análise de conteúdo, explorando as configurações latentes e explícitas da docência nessas universidades.

\section{FAIXA ETÁRIA E CONDIÇÕES DE TRABALHO dOS DOCENTES PESQUISADOS}

Entre os docentes estudados, analisamos a faixa etária como uma característica sociodemográfica e em relação às condições de trabalho, exploramos: contrato em relação à dedicação ao trabalho, vínculos estabelecidos com a instituição, cargos ocupados, ocupações concomitante à docência, funções desempenhadas e satisfação com a carreira.

Entre os professores da Universidade BR, havia maior concentração de docentes na faixa de idade a partir dos 45 anos, e no grupo de docentes da Universidade AR havia uma distribuição mais equitativa entre mais jovens e mais velhos, com faixa etária variando de 20 até 74 anos.

Essa variação na faixa etária, pode ser explicada pela forma de ingresso dos docentes nas universidades estudadas. Na Universidade AR, havia docentes ali, alunos de graduação; na Universidade BR exigia-se, no mínimo, a graduação completa. Além disso, observou-se maior flexibilidade nas formas de ingresso na Universidade AR devido à possibilidade de contratos temporários e voluntariado ser uma situação comum. Desse modo, a entrada na docência dos professores brasileiros ocorria mais tarde em relação aos argentinos, pois o ingresso era baseado em titulação e concurso.

Nessa perspectiva essa caracterização dos docentes está articulada às condições de trabalho em que estão inseridos, conforme poderemos relacionar a partir dos dados sobre condições trabalho.

Em relação ao contrato de dedicação ao trabalho, a dedicação exclusiva ou contrato de trabalho de 40 horas semanais na universidade chegam a 100\% na Universidade BR entre os docentes da Engenharia e da Educação e $82 \%$ dos docentes da odontologia . Por outro lado, na Universidade AR, o índice máximo de professores foi de $20 \%$ na educação, seguidos por $19 \%$ na engenharia e $9 \%$ na odontologia. Os demais docentes ainda se dividem em dedicação semi-simples (20 horas) e simples (10 horas). Nas três áreas, verifica-se que a maior parte dos docentes são de dedicação simples: $70 \%$ na engenharia, $69 \%$ na odontologia e 68 na educação.

Concomitante ao tempo de dedicação ao trabalho, outra distinção entre o grupo de docentes estudados é a condição de designação para o cargo nas diferentes áreas. Novamente, na Universidade AR há menor número de docentes efetivados e ainda, a existência de categorias que distinguem os docentes em função da designação e remuneração. Fazem parte desse grupo, os professores interinos que são designados para o cargo temporariamente e aguardam concurso e os professores regulares que são professores concursados. 
Nessas condições, os professores ainda podem se diferenciar em função de recebimento ou não de remuneração, pois há professores que não recebem salário por seu trabalho. São comumente chamados de ad honorem ${ }^{5} \mathrm{e} / \mathrm{ou}$ adscriptum 6 .

Em relação aos vínculos, entre os docentes da Universidade BR encontrou-se quase $100 \%$ de efetivos nos três cursos. Entre os docentes da Universidade AR, prevaleceu o contrário, menos docentes efetivos e significativa quantidade de interinos nos diversos cursos, sendo expressivo a quantidade destes últimos na educação (64\%), seguido pela engenharia (40\%) e odontologia (19\%).

Outro aspecto que contrasta fortemente nas duas universidades diz respeito à proporção de professores que estão no topo da hierarquia dos cargos docentes, na condição de Adjunto, Associado e Titular. Na Universidade AR, poucos docentes são Adjuntos, Associados ou Titulares. A representação máxima desses cargos encontrada foi na Engenharia: 33\% de docentes. Os docentes com cargos de auxiliares (Jefe de trabajo práctico, Auxiliar de primera e Auxiliar de segunda) correspondem até a $80 \%$ dos professores como na Odontologia e Educação.

$\mathrm{Na}$ Universidade BR encontrou-se o inverso, somente na área de Odontologia é que há docentes que ocupam cargos de auxiliares, compondo um grupo residual equivalente a $8 \%$ do total.

Essa condição está relacionada a especificidade da organização do trabalho nas duas universidades, pois na universidade BR, como em todas universidades federais do Brasil os professores se organizam por departamento e possuem um carreira comum regida nacionalmente. Isso implica a possibilidade de progressão individual por meio de tempo de serviço combinado com formação e produção acadêmica.

$\mathrm{Na}$ universidade AR, os docentes são organizados em cátedra, que possui uma estrutura hierarquizada em forma piramidal, com base composta pelos docentes auxiliares e na ponta os professores: adjunto, associados e titulares. Esse conjunto de professores compõe uma equipe de cátedra sob a orientação de um titular, cuja ocupação é de caráter vitalício, sendo substituída por meio da morte ou aposentadoria desse professor. Portanto, o acesso aos cargos mais elevados é derivado do tempo de docência, independente da titulação e dependente da mobilidade sociodemográfica de cada equipe. Essa organização é bastante vigente em outras universidades nacionais argentinas.

Nesse contexto, outro aspecto que perpassa a situação dos docentes na Universidade AR, e que se articula com essa condição de trabalho é o exercício de outras ocupações concomitante à docência na universidade. Comparados com os docentes da Universidade BR, constata-se que, os professores da Universidade AR, mais de $80 \%$ dos docentes combinam 0 exercício docente com outras ocupações fora da universidade.

\footnotetext{
${ }^{5}$ O sentido etimológico do termo ad honorem encontra-se relacionado com o sentido em latim "Para as honras, como título de glória. Foi nomeado ad honores, isto é, para um cargo ou função meramente honoríico." Assim, esse termo traduz bem o sentido do professor ad honorem na Argentina, aquele que trabalha pelo título em si pois não recebe remuneração em troca.

${ }^{6}$ Traduz-se em português como adscrito que pode ter os seguintes sentidos: "Acrescentado, aditado, aumentado, registrado. sm 1 Colono sujeito ao regime da adscrição. 2 Servo de criação." No caso do docente adscriptum é aquele que é agregado junto a equipe. (FERREIRA, 1986)
} 
Ao responderem sobre as funções que desempenham na universidade, considerando as funções de ensino, pesquisa, extensão e gestão, verificou-se predominância, entre os docentes da Universidade $\mathrm{BR}$, de três ou quatro funções completas, ultrapassando o percentual de $60 \%$ de respostas.

Já na Universidade AR, a tendência foi acumular, no máximo, duas funções. Mas na Engenharia e Odontologia, o desempenho de apenas uma função foi mostrado por mais de $50 \%$ dos pesquisados. Entre os professores da Educação da Universidade AR, o comportamento foi diferente, a maioria desempenha, duas a três funções.

Todavia, em ambas as universidades o ensino é a atividade em que todos os docentes estão envolvidos, combinando-o com as demais funções. Aliás, ao serem indagados sobre suas preferências entre as funções que podem assumir como docentes universitários, tanto na Universidade BR quanto na Universidade AR, o ensino figura como a atividade preferida entre todas as áreas.

Verificou-se também que os docentes das duas universidades levam trabalho extra para seus domicílios, sendo que a frequência de três ou mais vezes semanalmente foi elevada entre boa parte dos professores, principalmente na universidade BR: educação(88\%), engenharia(41\%), odontologia(66\%) e na universidade AR: educação(71\%), engenharia(30\%) e odontologia(20\%).

Embora com condições de trabalho contrastantes, verificou-se que os docentes da universidade AR tenderam a demonstrar índices de satisfação com 0 exercício da docência de maneira muito semelhante aos da universidade BR. Somente na odontologia BR é que apenas $49 \%$ dos docentes declaram satisfeitos, entre os demais, tanto na universidade BR quanto na universidade $\mathrm{BR}$, mais de $50 \%$ declararam que estão satisfeitos a muito satisfeitos com a carreira. Respectivamente, na universidade BR, engenharia $(83 \%)$, educação $(55 \%)$ e na universidade $A R$, odontologia $(90 \%)$, engenharia $(77 \%)$, educação $(56 \%)$.

\section{ANÁLISE dAS CONFIGURAÇÕES DA DOCÊNCIA NAS UNIVERSIDADES BR E AR}

A análise da docência nas universidades BR e AR a partir das áreas da Engenharia, Odontologia e Educação, evidenciou uma diversidade de configurações da docência que nos desafia a produzir uma síntese respeitando essa diversidade sem perder a capacidade de análise. Assim, agrupamos as semelhanças e diferenças encontradas nas seguintes perspectivas:

Semelhanças: agrupam características compartilhadas pelo grupo de professores dos diferentes cursos nas duas universidades;

Especificidades: são as singularidades de algum curso ou universidade em relação aos demais;

Contrastes: são as diferenças de alta intensidade marcadas por cursos ou universidades;

Desta forma, prosseguimos as análises baseando-se na seguinte organização. 
Semelhanças: ensino como atividade comum e preferida, bom nível de satisfação com a carreira, muita frequência de trabalho extra realizado em domicílio.

Contrastes: docentes mais envelhecidos na Universidade BR do que na Universidade AR; grande número de associados e adjuntos na Universidade BR em oposição ao maior número de auxiliares na Universidade AR; maior número de dedicação exclusiva entre os da Universidade BR e maior número de dedicação simples entre os da Universidade AR; ocupações extras à atividade docente em menor número na universidade BR em oposição à mais ocupação com outras atividades entre os da Universidade AR; mais vínculos efetivos entre os da Universidade BR e menos, entre os da Universidade AR; três a quatro funções docentes desempenhadas entre os da Universidade BR e o máximo de duas funções entre os da Universidade AR; realização de trabalho extra em domicílio mais vezes por semana entre os da Universidade BR e menos, entre os da Universidade AR;

Os dados relativos à faixa etária revelaram uma diferença de comportamento, ou seja, concentração de docentes mais velhos na Universidade $\mathrm{BR}$ em relação à da Universidade AR. Essa análise distoa da análise de Musselin (2011), que atribui a percepção do envelhecimento aos contextos de massificação do ensino, pois o Brasil não massificou o ensino e, no entanto, apresenta esse comportamento. E a Argentina tem a educação superior massificada e apresenta grupo de docentes mais jovens.

Essa análise pode ser explicada pela diferença no fluxo de ingresso na profissão e suas peculiaridades entre os países, o que coincide com análise de Tenti Fanfani (2007). Segundo ele, a idade pode relevar mecanismos reguladores da profissão em termos institucionais.

Nesse sentido, a presença de muitos docentes mais novos na Universidade AR está relacionada ao fato de que o ingresso na docência universitária, nesse país, não demanda formação completa em graduação e também de pós graduação. Esse fato posiciona a condição da docência universitária na Universidade AR mais próxima das análises sobre a docência da educação básica em geral, tal como apontado por Tenti Fanfani (2007). Segundo ele, a docência da educação básica é um dos ofícios mais antigos e que, contrário às profissões clássicas, os critérios são mais flexíveis, permitindo a entrada precoce, não exigindo estudos e exames de ingresso.

Ademais, vale lembrar que, a organização dos docentes em cátedra na Argentina, com hierarquização dos cargos em torno de auxiliares e professores, também favorece 0 ingresso de docentes mais novos, pois a base do grupo docente é constituída mormente por auxiliares.

Embora o ensino seja elemento comum a todos os docentes, as demais condições norteadoras do exercício da docência são bastante distintas entre eles, principalmente quando se comparam as universidades. E, nesse sentido, constatou-se um processo mais intenso entre os professores da Universidade BR em relação à conformação da docência quando comparado com os docentes da Universidade AR, pois, a docência de ensino superior na Universidade BR, exige um trabalho com dedicação integral, que demanda formação mais prolongada e constitui uma carreira regida por estatuto nacional.

Essa situação contrastante entre os docentes de ambas as universidades é condizente com a análise de Nóvoa (1995a) sobre a importância da atividade docente como ocupação principal para a valorização da docência e sua afirmação profissional. No 
caso da Universidade AR, é muito forte a prevalência da docência como atividade residual e essa situação é desfavorável, tal como afirma Nóvoa (1995a), porque leva os docentes a buscar seus estímulos econômicos e profissionais fora do magistério.

No caso dos docentes da Universidade BR, parece coincidir com a análise desse autor. Assim, segundo Nóvoa (1995aㅡ), a vivência da docência como atividade principal favorece outros aspectos da situação de trabalho, tais como: estabelecimento de carreira, mais permanência numa mesma instituição e maior identificação dos professores com seus locais de trabalho.

Nesse sentido, a docência entre os professores da Universidade BR é assumida profissionalmente e abrange mais funções, sendo uma ocupação de tempo integral. No entanto, os docentes tendem a declarar que as atividades de trabalho extrapolam o tempo institucional, sendo realizadas em domicílios compondo horários extras. Esse aspecto coincide com as análises de autores como Musselin (2011) e Sguissardi (2010), ou seja, tem aumentado a quantidade de trabalho e de funções dos docentes universitários nos últimos tempos tendo em vista as transformações das universidades em âmbito mundial.

Desta forma, a existência de uma carreira formalizada no Brasil, embora preserve em alguns aspectos a docência universitária como a manutenção da igualdade de condições entre docentes de distintas áreas, mostra-se frágil na capacidade de preservar a intensidade do trabalho docente, pois sua base é meritocrática, sustentada em progressão por meio de titulação e produção dos docentes. E essa perspectiva converge com o cenário analisado pelos autores sobre as características das universidades contemporâneas.

Por outro lado, a docência entre o grupo de professores da Universidade AR configurou-se um trabalho precário, tal como definido por Antunes (2005). Pois apresenta traços de flexibilização nas formas de contratação, com muitos professores na condição de interinos e ad honoren e ainda, a ausência de uma carreira em comum e institucionalizada.

Esses traços são mais marcantes no caso daqueles que vivem somente da docência, como os docentes da Educação. Estes, em relação às demais áreas, apresentaram condições menos favorecedoras como: mais docentes designados como interinos, mais trabalho em casa e piores condições de trabalho em geral. Neste caso, a ausência de formalização do trabalho tem acentuado a precarização em outros aspectos relativos à rotina do trabalho acadêmico.

Essa peculiaridade evidencia que a ausência de política de afirmação profissional dos docentes, seja na esfera nacional ou institucional, regulamentando condições de trabalho, de ingresso, carreira, formação, atividades desempenhadas e outras, pode levar a desigualdade de condições entre o grupo de docentes de uma mesma instituição. Como apontado por Oliveira e Assunção (2010), as condições de trabalho em geral, na atualidade bem como do trabalho docente, refletem um modo de organização social em estreita relação com os modos de produção predominantes na sociedade.

Com efeito, a análise das configurações em torno das condições de trabalho reforçam o conceito norteador desta pesquisa, isto é, entender a da docência considerando a profissão docente e as representações e ações próprias do ensinar conjugado com as 
demais funções inerentes ao contexto universitário, conforme apresentado por Cunha (2010).

Essa afirmação se sustenta na hegemonia do ensino como atividade preferida pelos docentes das diversas áreas, tanto da Universidade BR quanto da Universidade AR, assim como a expressiva satisfação com a carreira. Tais representações são convergentes em cenários muito distintos em termos de configurações da docência, pois se evidencia uma clara diferenciação e segmentação, principalmente na universidade AR.

\section{CONSIDERAÇõES FINAIS}

Ao analisarmos as configurações da docência na universidade BR e na universidade AR consideramos relevante e pertinente desenvolver estudos sobre a condição dos docentes para problematizar as políticas e práticas de educação superior.

As peculiaridades locais evidenciadas pelos docentes, embora não possam ser generalizada para todos os docentes de universidades públicas de cada país, explicitam perspectivas distintas na condução da educação superior, tanto no âmbito das instituições quanto da política educativa nacional.

A primeira vista podemos concluir que os docentes brasileiros evidenciaram melhores condições de trabalho que os docentes argentinos. No entanto, essa evidência não pode ser desvinculada de uma análise da oferta de educação superior nos dois países aqui estudados com as seguintes características: massivamente pública na Argentina e massivamente privada no Brasil.

Esse contexto nos provoca a indagar: como conciliar democratização da educação superior com condições dignas de docência?

A condição dos docentes reflete as transformações da educação superior e evidenciam uma relação entre segmentação e diferenciação entre os docentes, reforçando as perspectivas apontadas por Altbach (2009). A diferenciação manifesta-se nas distintas condições de trabalho e pode ser vista entre ambas as universidades e no interior de uma mesma universidade, principalmente na universidade AR. No entanto, em alguns aspectos a diferenciação é tão extremada, ou seja, gera uma distancia tão grande entre os docentes, que podemos designar de segmentação, porque posicionam os docentes em condições de desigualdades entre si.

Cabe entender que a segmentação e diferenciação na docência são efeitos de mecanismos institucionalizados que tem se mostrado insuficiente na preservação das condições da docência e afeta esses sujeitos em suas relações cotidianas. Tais condições promovem a perda de visão de um coletivo; cinde a possibilidade dos docentes compartilharem experiências e produção crítica de conhecimentos e, fragiliza a profissionalidade dos professores porque perdem perspectivas comuns em termos de trabalho acadêmico.

Entender a dimensão política posta nessas condições implica reconhecer os docentes como sujeitos que produzem e socializam conhecimentos relevantes para a sociedade, principalmente na América Latina, onde a universidade pública tem uma função importante no aporte à pesquisa.

Preservar esses sujeitos das interferências privadas na condução de suas ações demanda condições de trabalho que fortaleçam a dimensão coletiva da docência e sua 
necessária liberdade na produção acadêmica, possibilitando a manutenção de valores próprios à docência. Como vimos, os docentes mesmos em condições muitos contrastantes mantem uma satisfação com o exercício da docência e tem o ensino como uma atividade comum.

Trata-se de um trabalho regido por valores materiais e simbólicos que não se mensura somente por aspectos estruturais, mas pela interação que se estabelece na relação com o outro em meio à produção e socialização de conhecimento. E nesse sentido, a condição dos docentes reflete a própria possibilidade de constituição da universidade como espaço regido por valores intrínsecos à uma ética científica. Como assinalou Santos (1995, p.204), valores como "o comunismo, o desinteresse, o universalismo e o cepticismo organizado".

Ainda que esses valores possam ser considerados como tributários de uma universidade europeia, de características elitista e descontextualizada com os tempos atuais, uma suposta reinvenção da universidade não pode ignorar o compromisso com a educação superior em nosso continente em função de uma adesão voluntária à mecanismos mercadológicos globais.

Desta forma, consideramos que as configurações docentes nos mostram que não há como tratar de acesso, qualidade e equidade na educação superior sem abordar o sentido que a profissionalidade docente assume nesse contexto. A construção desse sentido demanda condições materiais dignas para o exercício da docência e possibilidade de elaboração coletiva de um projeto condizente com uma universidade que advoga a favor da educação superior como bem público.

\section{REFERÊNCIAS}

ALTBACH, Philip. G. (org.) REISBERG, Liz; RUMBLEY, Laura E. Trends in Global Higher Education: Tracking an Academic Revolution.UNESCO: France, 2009. Disponível em: www.uis.unesco.org Acesso em: 10 jul. 2016.

ANTUNES, Ricardo. Adeus ao trabalho: ensaio sobre as metamorfoses e a centralidade do mundo do trabalho. 10ª . Ed. São Paulo: Cortez, 2005AZEVEDO, 2010.

CATANI, Antônio. M. e OLIVEIRA, José. F. de Educação Superior no Brasil: Reestruturação e metamorfose das universidades públicas.Petrópolis: Vozes, 2002.

CHAUÍ, Marilena. A universidade pública sob nova perspectiva. Rev. Bras. Educ., Rio de Janeiro, n.24, dez. 2003. Disponível em: http://www.scielo.br/pdf/rbedu/n24/n24a02.pdf. Acesso em: 01 out. 2016.

CONTRERAS, José. A autonomia dos professores. São Paulo: Cortez, 2002.

CUNHA, Maria Isabel. Docência Universitária. In.: Oliveira, D. A.et al( 2010) Dicionário de trabalho, profissão e condição docente. Belo Horizonte: UFMG, FaE. CD-ROM.

CUNHA, Maria Isabel. O lugar da formação do professor universitário: a condição profissional em questão. In: CUNHA, M. Is. (org.) Reflexões e práticas em pedagogia universitária.Campinas, SP: Papirus, 2007.

DIDRIKSON, Axel. Contexto Global y regional de la educación superior em América Latina y el caribe. In: Gazzola, Ana L.; Didrikson, Axel. Tendencias de la Educación superior em América Latina y el caribe. Caracas, IESALC-UNESCO, 2008

FERREIRA, Aurélio B. de Holanda. Novo dicionário Aurélio. Editora Nova Fronteira. 1986.

ENGUITA, Mariano F. A ambiguidade da docência: entre o profissionalismo e aproletarização. Revista Teoria e Educação, Porto Alegre, n. 04, p. 41-61, 1991. 
GAZZOLA, Ana Lúcia. Políticas Públicas para a Educação Superior, para a Pesquisa e para a Profissão Docente no Brasil, América Latina e Caribe: Cenários, Desafios e Avanços. UFMG: FaE, junho de 2010 (Power point) Disponível em: www.fae.ufmg.br/posfae

GOMES, Alfredo. Globalização, Educação Superior e o novo PNE. Belo Horizonte: UFMG, FaE, maio de 2011.

KRAWCZYK, Nora y WANDERLEY, Luiz, (org.) América Latina. Estado e reformas numa perspectiva comparada. São Paulo: Cortez editora. 2003

LANG, Vincent. PROFISSIONALIZAÇÃO DOCENTE. In: Van Zanten, Agnès. Dicionário de educação. Petrópolis, RJ: Editora Vozes, 2011. Páginas 321-325.

LEHER, Roberto. Por una reforma radical de las universidades latinoamericanas. Rosario, Argentina: CLACSO: Homo Sapiens Ediciones, 2010. 378 p.

MOLLIS, Marcela. Geopolítica del saber: biografías recientes de las universidades latinoamericanas. In: Vessuri, $\mathrm{H}$. Universidad y investigación científica: convergencias y tensiones.Buenos Aires: CLACSO: UNESCO 2006.

MOROSINI, Marília. C. \& NOSIGLIA, Maria Catalina. (1998) Políticas de Educación Superior en Argentina y Brasil un enfoque comparado.20th Annual European Higher Education Society. EAIR. Espanha, Set., 1998.

MUSSELIN, Christine. ENSINO SUPERIOR. In: Van Zanten, Agnès. Dicionário de educação. Petrópolis, RJ: Editora Vozes, 2011. Páginas 321-325.

NÓVOA, António. Modelos de análise em educação comparada: o campo e a carta. In: Sciences de l'educationpourl'ère nouvelle, n.2-3, 1995.

OLIVEIRA, Dalila Andrade; ASSUNÇÃO, Inês. Condições de trabalho docente In.: Oliveira, D. A.et al( 2010) Dicionário de trabalho, profissão e condição docente. Belo Horizonte: UFMG, Faculdade de Educação. CD-ROM.

RODRIGUES, Maria de Lourdes. Sociologia das profissões. 2ª Ed., Oeiras, Portugal: Celta Editora, 2002.

SANTOS, Boaventura S. Da idéia de universidade a universidade de ideias. In.SANTOS, Boaventura S. Pela mão de Alice: O social e o político na pós-modernidade. São Paulo:Cortez, 1995. P. 187 - 234.

SGUISSARDI, Valdemar. Produtivismo acadêmico. In: OLIVEIRA,D.A.; DUARTE, A.M.C.; VIEIRA, L.M.F. Dicionário: trabalho, profissão e condição docente. Belo Horizonte: UFMG/Faculdade de Educação, 2010. CDROM

TARDIF, Maurice; LESSARD, Claude. 0 trabalho docente: elementos para uma teoria da docência como profissão de interações humanas. Petropólis, RJ: Vozes, 2009. 5a . Ed.

TENTI FANFANI, Emílio. La condición docente: análisis comparado de la Argentina, Brasil, Perú y Uruguai. Buenos Aires, Argentina: Siglo XXI, 2007.

UNESCO. Conferência Mundial sobre Ensino Superior. Paris: 2009. Disponível em: www.unesco.org Acesso em: 10 jul. 2016.

ZEMELMAN, Hugo. Algunas reflexiones metodológicas a partir del problema de las investigaciones comparativas. In: KRAWCZYK, Nora y WANDERLEY, Luiz, (organizadores), América Latina. Estado e reformas numa perspectiva comparada. São Paulo: Cortez Editora, 2003. 